\title{
Modeling Virtual Road Scenarios for Driving Simulators: a Comparison of 3D Models with Different Level of Details
}

\author{
Barbara Piga \\ Giandomenico Caruso \\ Alfonso Ferraioli \\ Lorenzo Mussone
}

Abstract

The paper presents a comparative study of a set of four 3D virtual scenarios with four different Levels of Details and the assessment of their performances for driving simulators. The goal of the experiment is to study the efficacy of the representation of each scenario since their realism affects driving behavior and, consequently, the reliability of the driving experience and thus the virtual driving tests themselves. Many elements influence the interaction between the driver, the vehicle, and the environment. The model was elaborated considering six main classes of variables, namely: I) Road infrastructure; 2) Vehicle characteristics and its performance; 3) Buildings and all other artefacts visible from the vehicle; 4) Events (pedestrians, signalization, animals, lighting etc.); 5) Environmental conditions (rain, fog, night-time and visibility); 6) Traffic (with different levels of service). The experimental investigation was conducted on a sample of young people (19-25 years old) driving along the same road path. The different LODs of the scenarios were presented in random sequence to participants in order to reduce possible bias. A car-simulator equipped with a seat, pedals, gear, steering wheel, and 3 monitors for the panoramic view was used to run the tests. The evaluation of the drivers' reactions is based on psycho and physiological parameters collected during the simulated driving experience. The impact of the different road scenarios on the driving behavior is discussed in the paper.

Keywords

Level of Detail; car-simulator; 3D model; ecological validity; representation protocol.

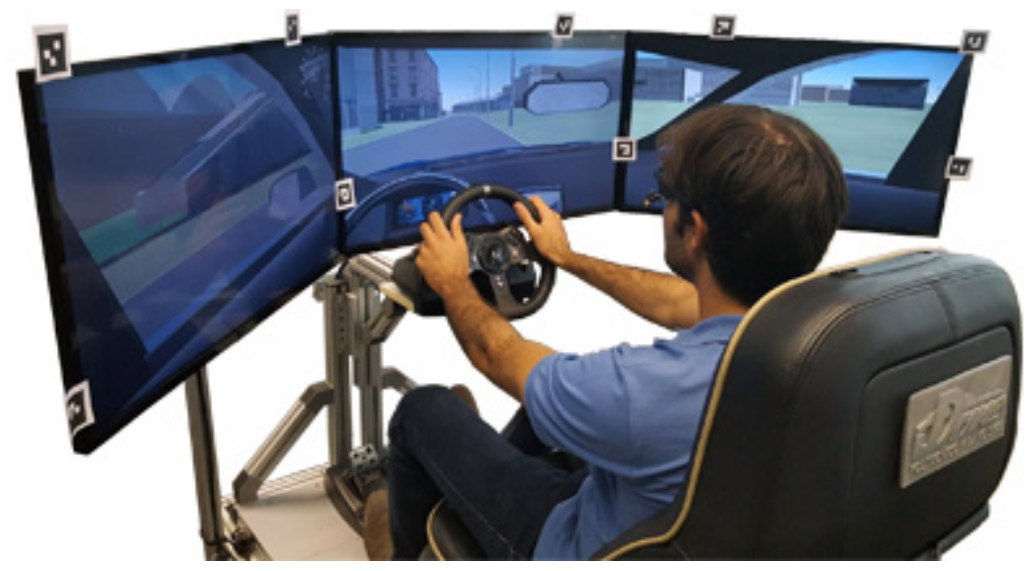




\section{Introduction}

The evaluation of driving behaviors through testing sessions with a car-simulator is the final goal of the undergoing research by the interdepartmental laboratory i.Drive [I] (POLI$\mathrm{MI})$. This paper focuses on a specific part of the research, that is the production of virtual scenarios with different Level of Detail (LOD) and the comparative analysis of their usage in the i.Drive car-simulator. To do that, four driving scenarios, representing the same area (and the same path), have been modeled with different LODs in order to study their performance; the goal of the research is to define a standard procedure, possibly suitable for different driving simulation software, for minimizing the efforts of production. The type of car-simulator addressed for the study is the one that allows a naturalistic interaction, i.e. an interaction comparable to the real one; in other words, a car-simulator with steering wheel and pedals for guiding the visual simulation projected on a panoramic screen, representing the car windscreen (fig. I).

The construction of such scenarios could be complex and time consuming, especially when the research aims at evaluating the behavior of a driver in conditions very close to real ones, i.e. which implies the production of a realistic virtual model. The problems to face are of different kinds, e.g. finding updated bases, checking, cleaning, and eventually updating 2D maps, 3D model reconstruction, texturing or facades design, and so on. Online dataset can support the implementation of these elements by providing useful information about buil-

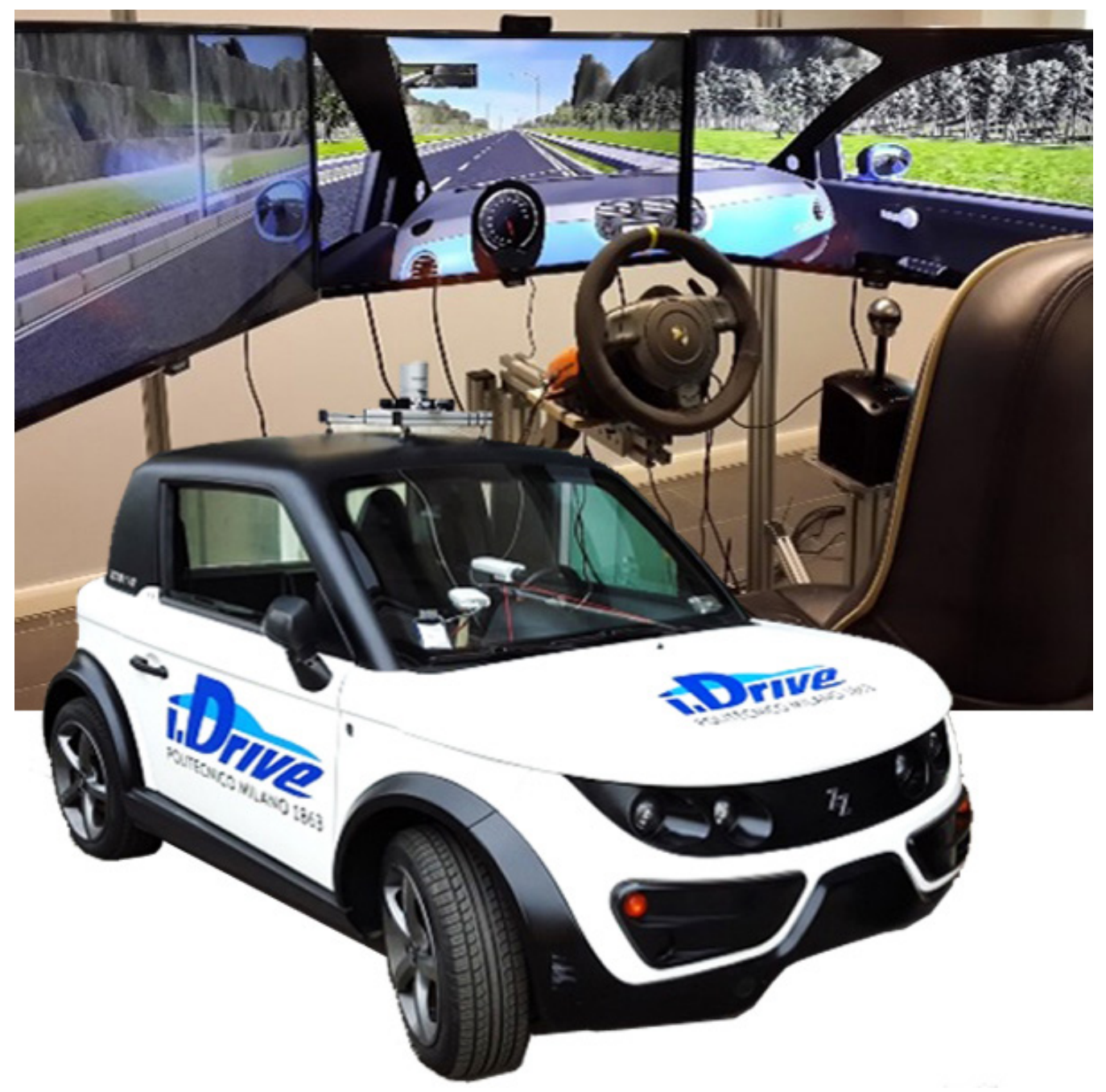


dings geometry and location as well as other urban elements such as streets, squares, parks, and similar. However, often these data are not enough; on-site data collection and manual post-processing are still necessary to finalize the virtual scenario. Moreover, files generated with different software might face interoperability problems, and its final performance is also relative to the car-simulator software to use. Certainly, researchers that are going to build scenarios for driving simulation have to address multiple issues. How realistic should the simulation be in order to compare a simulated driving scenario with a real one? What kind of elements must be rendered? Is it possible to skip some of them? Which is the minimum render quality? Many factors affect possible answers and surely a compromise has to be taken for counterbalancing the required effort with available resources.

\section{Research framework}

The use of computer-based and interactive 3D representations of real environments in spatial and environmental planning has already been an active research field since almost 20 years [Bosselmann, Craik 1985; Marans, Stokols 1993; Batty 1997; Batty et al. 1998; Bosselmann 1998; Pittman 1992; Sinning-Meister et al. 1996; Skauge 1995]. More recently, as a consequence of the increased availability of qualified 3D data and improved capabilities of authoring and visualization system, virtual 3D city models have been used for the presentation and exploration of heterogeneous spatial data in research projects and in practice.

Virtual 3D models are used for a variety of applications, and the way they are prepared is generally not standard; for this reason, the Open Geospatial Consortium (OGC) develops a procedure for their standardization through the concept of Level of Detail (LOD). Actually, the term LOD can be associated to virtual simulation in two main ways; it can be related to the 3D model itself or to the relationship between the virtual camera and the model. In the first case, the concept of LOD is related to a specific model file, that is the CityGML (City Geography Markup Language), defined by the Open Geospatial Consortium as "an open data model and XML-based format for the storage and exchange of virtual 3D city models" [Kolbe 2009, p. I5] able to embedded different LOD, including objects semantics, in the same model. The LODs are an open standard defined for facilitating the wide exchange of geospatial three-dimensional information for different purposes and disciplines. The second case is generally related to a computer graphics technique which reduces the complexity of a 3D model representation according to the position of the virtual camera inside the 3D scene [Luebke et al. 2003]. The aim of this technique is to speed up the rendering process of complex and wide 3D models assuming that human sight is not able to elaborate details of relatively distant objects.

CityGML organizes virtual 3D city models according to four main aspects (semantics, geometry, topology, and appearance) and all objects can be represented with different LODs (LOD 0 regional, landscape; LOD I city, region; LOD 2 city districts, projects; LOD 3 architectural models (outside), landmarks; LOD 4 architectural models - interior). For our purposes it is relevant to notice that CityGML is also structured into thematic (semantic) modules, as follows: Digital Terrain Models; Sites (buildings, bridges, tunnels); Vegetation (areas, volumes and solitary objects with vegetation classification); Water bodies (volumes, surfaces); Transportation facilities (both graph structures and 3D surface data); City furniture; Generic city objects and attributes; User-definable (recursive) grouping [Kolbe 2009; Citygml Wiki]. Suggestions to improve that specifications are also on-going recently [Bijecki et al. 20 I 4; Bijecki et al. 20 I 4-20 I 6]. Recent research in the acquisition of LOD 3 models is focused on automatisation, especially automatic detection of windows and other facade details [Becker 2009, 20I I; Van Gool \& Martinović 20 13]. Developments can be in capturing and processing 3D geodata target, the automated processing of geometrical facade details such as windows and doors [Becker et al. 2008; Mayer, Reznik 2007] and automated facade texture mapping methods [Frueh et al. 2005; Kang et al. 20 I0]. However, due to the increase in quantity of data sets with non-homogenous LODs, many issues are pointed out by some authors [Arroyo et al. 20 I5; Fan et al. 20 I 4; Touya \& Reimer 20 15]. 
If the goal of LOD in CityGML is the one of a standardization of virtual model itself for easing data exchange, in computer graphic the goal is to render efficiently the model. As a matter of fact, in computer graphics multiple representations of polygon meshes are differentiated by their number of faces, and their simplification is performed by algorithms that reduce the number of faces while attempting to retain visual fidelity [Luebke et al. 2003].

Other contributions on the subject of visual simulation are in the fields of landscape and environmental planning [Bishop, Lange 2005; Ervin 200 I; Lange 200 I; Pettit et al. 2008], urban planning and architecture [Counsell et al. 2006; Danahy 2005; Delaney 2000], geo-information science [Abdul-Rahman et al. 2006; Coors, Zipf 2005; Oosterom et al. 2008], and computer graphic science [Döllner et al. 2006; Döllner, Hinrichs 2000]. Applications to traffic simulations have been proposed since many years [Wang et al. 2008; Dols et al. 20 I6] and recent developments are also available in licensed software.

\section{Methodology}

According to the goal of the research, the scale of the case study, and the travel speed, the necessary LOD of virtual driving scenarios can vary. Moreover, if the speed is not constant different LODs might be necessary, i.e. a more detailed view is needed when the velocity decreases. In any case, the progressive render of details, that follows the user perspective in motion, make the real-time visualization of scenario more efficient. The scope of our research is to compare the efficiency of models with different LODs for running driving simulation at the neighborhood scale in order to properly approximate, through experiential simulation, the reaction of people to the simulated environment to the ones they would have in a real condition.

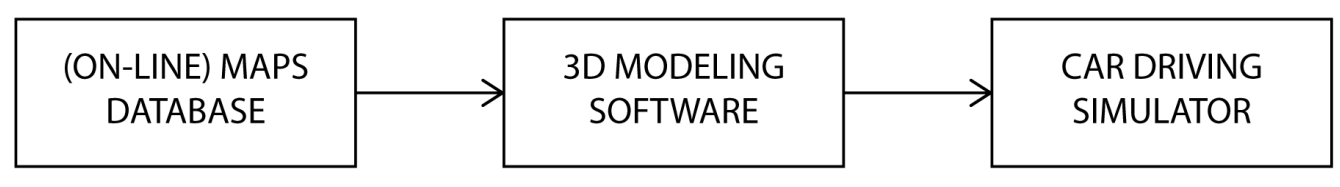

Three separate procedures were used for modelling virtual scenarios and two main aspects were evaluated: quality, i.e. the way an object is modeled and represented, and completeness, i.e. if all urban elements are depicted in the scenario. The methodological sequence of the virtual modelling procedures is shown in fig. 2.

In general, a driving scenario is composed of static elements (roads, buildings, road marking, vertical signing, perspective scenes), interactive elements (vehicles, pedestrians, unexpected obstacles), and dynamic elements (traffic lights). Once the driving area is identified and the basemap is acquired, it is necessary to start modelling, assembling and refining all its constituting elements.

The 2D map of the case study was the starting point to build up the scenario, and its extrusion allows to produce the 2.5 map of the case study area. Other fixed elements of the current scenario, such as walls, fences, sidewalks, roundabouts, were directly added in 3D environment. The roof of buildings was modeled as well. Lastly, the obtained model was exported and placed into a driving simulator software where moving vehicles and some other static elements have been added to the scenario, e.g. street signs, parked vehicles, lighting poles, plants, and so on.

Out of the described procedure three different models with different levels of detail were produced from LOD 0 (in our case a map representing the ground plane) as follows: LOD I with buildings as parallelepipeds (2.5D); LOD 2 buildings with roof structure; LOD 3: buildings with facade textures and other detailed architectural elements. 
Of course, the final performance of simulation depends on the overall quality of the 3D model, assuming that the characteristics of the personal computer running the simulation can also affect the final outcome.

\section{The driving simulator and the experimental set-up}

The impact of the different LODs on the driving task were evaluated through an experimental campaign conducted with 9 people, with an age between 19 and 25, using the driving simulator with the scenarios with different LODs. The driving simulator used for the experiment consists of a home-made fixed seating buck, a set of vehicle controls (force-feedback steering wheel, gear shifter and pedals) and three 32" full-HD monitors, which provide 175 degrees field of view to show the virtual driving scenario (fig. 3). The IPG Automotive CarMaker (CarMaker 2019) software was used for the virtual simulation of the scenarios. CarMaker is a vehicle simulation environment comprising intelligent driver models, detailed vehicle models and highly flexible models for roads and traffic.

So far, the driving scenarios with different LODs were simply tested on the simulator for a first appraisal and comparison of their performances; the testing phase with users is ongoing and the final results, based on more detailed elaboration of the collected data, will be presented in future publications.

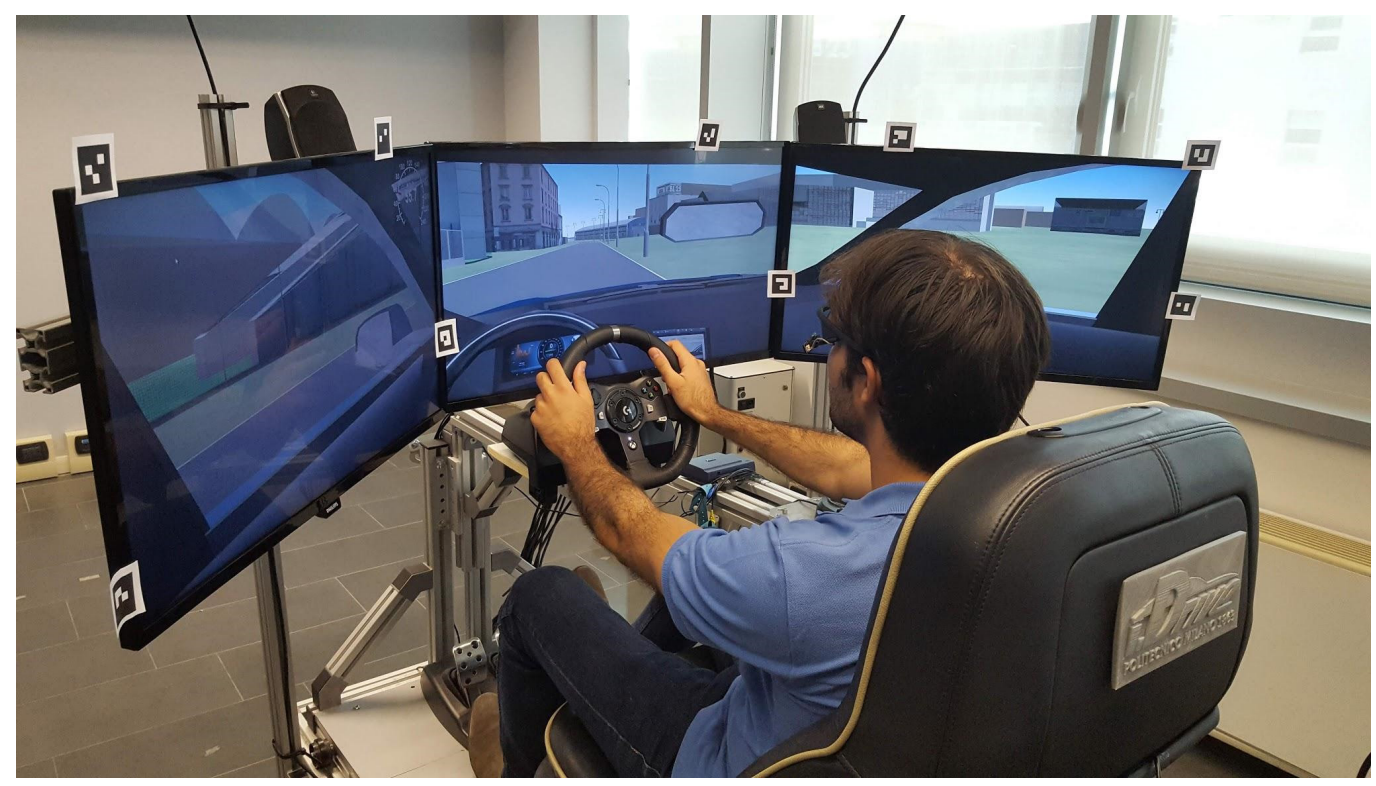

\section{Case study}

The case study application for testing the modeling procedures is the site of the Politecnico di Milano - Campus Bovisa (Engineering), La Masa area, located in the North-West of Milan. The modeled area is about $350 \mathrm{~m} \times 350 \mathrm{~m}$ wide, and the path of the driving simulation is about $1 \mathrm{~km}$ long, which is the public one-way ring road that runs along and in between the campus area. The area is mainly composed of isolated buildings (the university ones), surrounded by open spaces and fences.

The 3D models, used in this study, were built by using the 3D design software SketchUp@. At first, simply volumetric extrusions of the buildings base were modelled from the $2 \mathrm{D}$ CAD file, representing the planimetry of the area and the information of building elevation (fig. 4). Then, the roofs, calculated from the 2D map and the images provided by Google Earth(C), were modelled starting from the previous extrusions. 


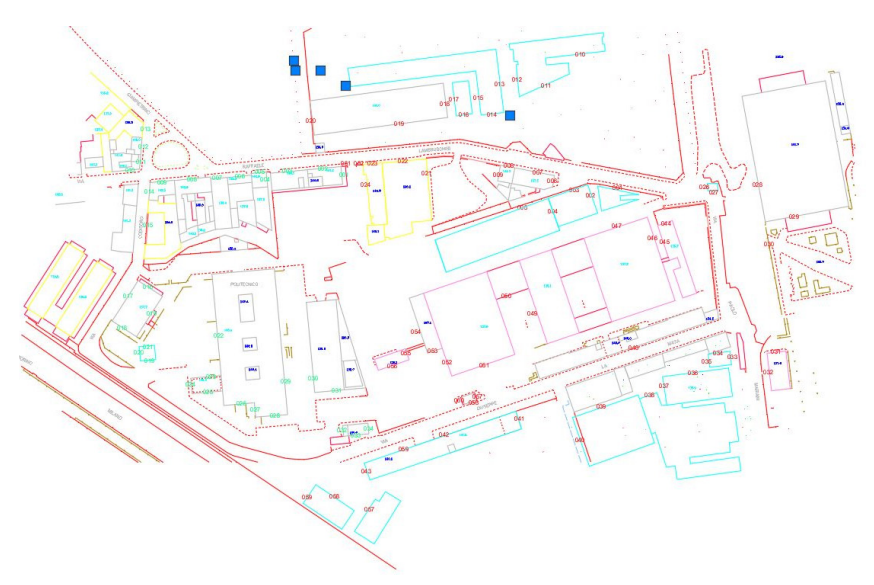

In parallel with the modelling activities, a site survey was conducted and photos of visible facades from the road were taken with a digital (non-professional) camera.The images were then organized and post-processed in order to be used in the 3D model. Every photo was, in fact, properly modified by deleting objects incidentally present (e.g. pedestrians, vegetation, vehicles, animals, and so on, and by correcting perceptual distortions (see for instance Fig. 5) with Adobe Photoshop(C). Non-accessible facades were reconstructed starting from pictures imported from Google Street ViewC.

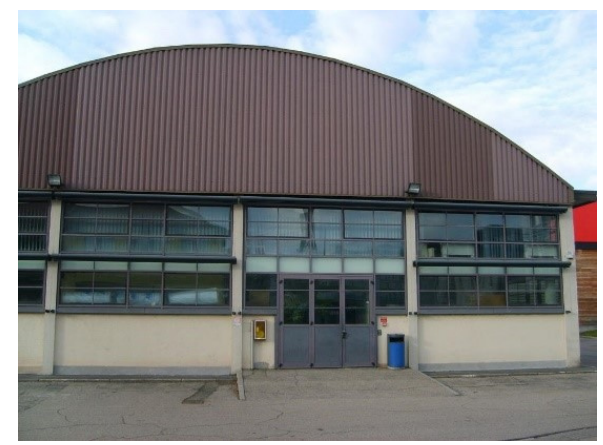

The post-processed facades images were imported as texture in SketchUp and applied one by one to the corresponding facade. The scenario was further improved by inserting other elements such as fences, walls and street lamp-posts. All the 3D elements were organized in SketchUp in five different layers (buildings, roofs, walls, fences, and lamp-posts) in order to export them in different files suitable for simulation software. The road network, instead, was imported in CarMaker from Google Earth@). In the CarMaker Scenario Editor, the correct width measures of each street were set for every road segment and road marking, and vertical signages were added by using a specific function. This type of process allows to get a unique path for all the scenarios with different LODs, and this eases the evaluation and comparison of their performance for driving simulation. Finally, the obj files were imported in CarMaker to create the virtual scenarios for the simulation.

The virtual scenarios were prepared having in mind the CityGML definitions of LODs; anyhow, for the scope of the study, some specific elements should be present in all scenarios, including the most simplified representation, i.e. the road signs. Consequently, the produced scenarios are not completely consistent with the OGC LODs definition, hence, we named them as "Level" (from 0 to 3) and not as LODs. The representation of the four virtual scenarios used for comparison is described below. 
Fig. 5b. Examples of

digital photos: the post-

processed image ready

to be applied in the $3 \mathrm{D}$

model.

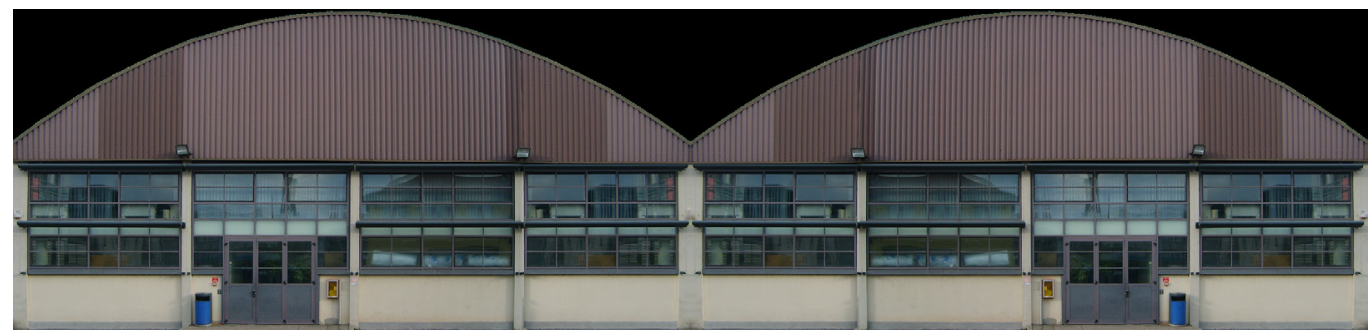

Level 0

It simply depicts the road, that is the carriageway, vertical signs and road markings (fig. 5).

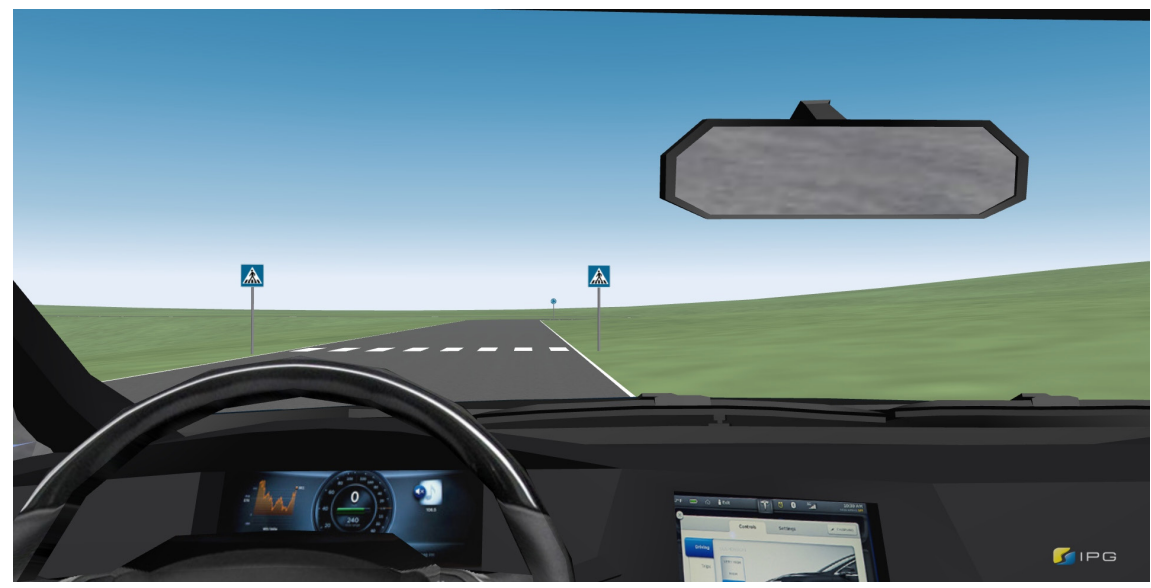

Level I

The .obj file containing all the buildings was added to the level 0 scenario. All buildings have the same color and neither the photorealistic facades nor the roofs were imported (fig. 6).

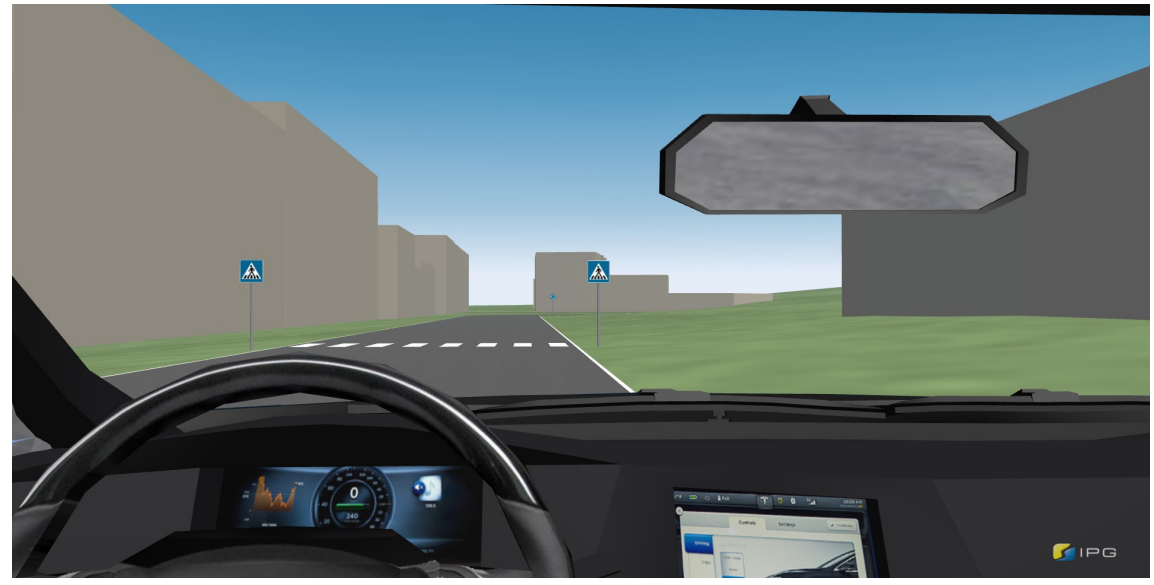


Level 2

Starting from the level I scenario, level 2 includes the .obj file containing all building roofs. All the roofs have the same color, which may be different from the one of the buildings (fig. 7).

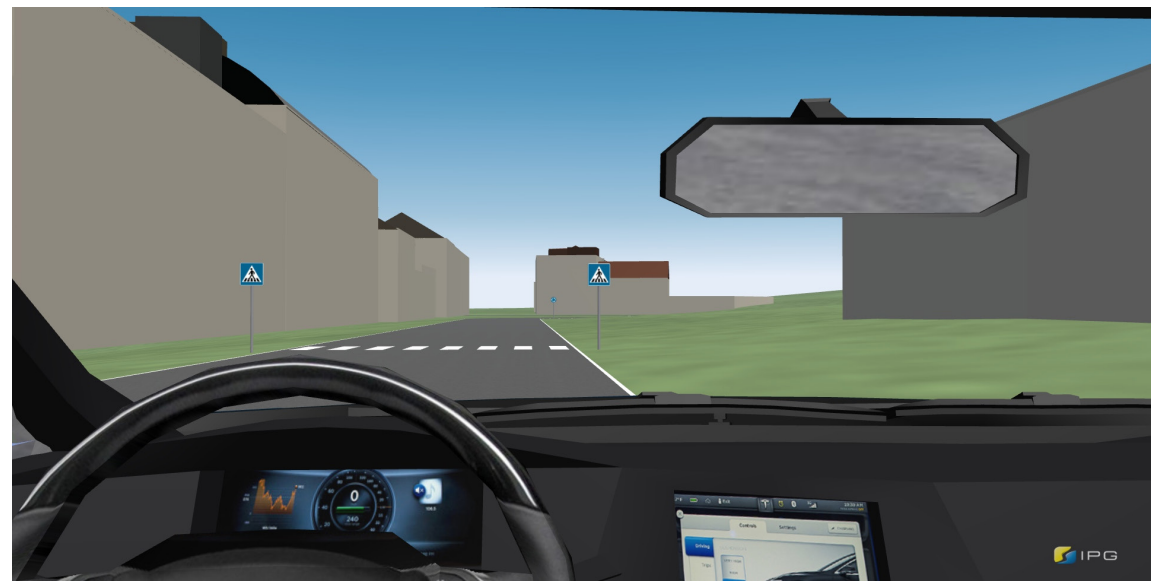

Level 3

Level 3 is the scenario with the highest level of detail. Buildings and roofs have been imported with their photorealistic materials. Moreover, fences, walls and street lamps have been added (fig. 8).

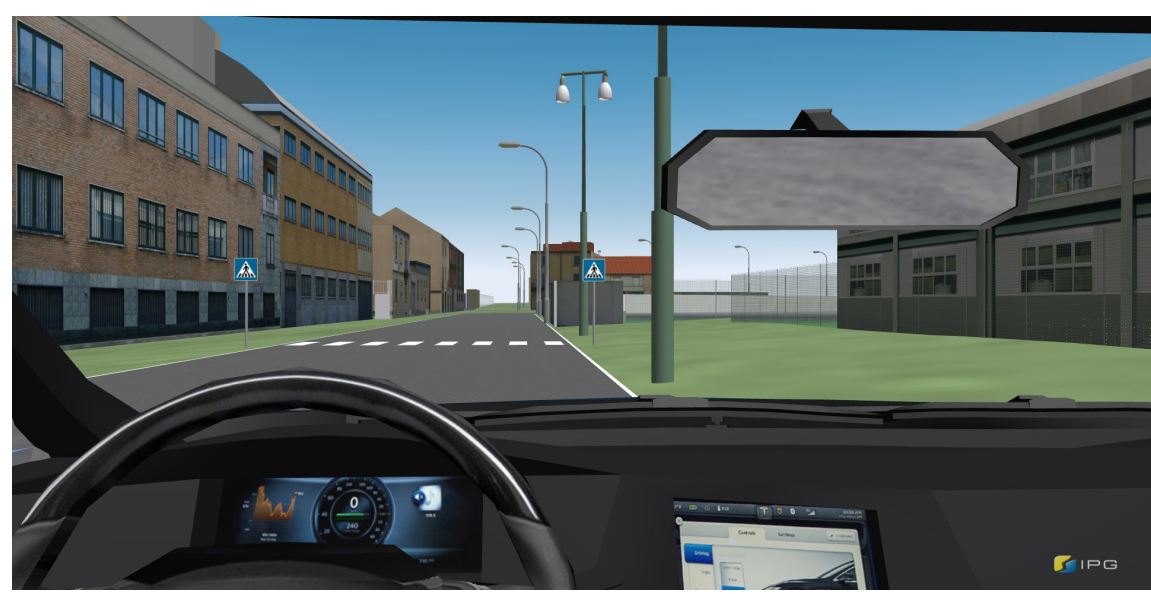


Table 3 lists the elements taken into consideration in the four levels for building the scenarios.

Table 3: Elements taken into account in the different models.

\begin{tabular}{|c|c|c|c|c|c|c|c|c|}
\hline & $\begin{array}{c}\text { Signage: } \\
\text { vertical signs and } \\
\text { road markings }\end{array}$ & Buildings & Roofs & Facades & Walls & $\begin{array}{c}\text { Lamp- } \\
\text { posts }\end{array}$ & Fences & $\begin{array}{c}\text { file size } \\
{[\mathrm{kB}]}\end{array}$ \\
\hline Level0 & yes & No & No & No & No & No & No & 28 \\
\hline Levell & yes & yes & No & No & No & No & No & I7I \\
\hline Level2 & yes & yes & yes & No & No & No & No & 207 \\
\hline Level3 & yes & yes & yes & yes & yes & yes & yes & 131,289 \\
\hline
\end{tabular}

\section{Description of the experiment}

To assess the impact of the proposed LODs on driving, an experimental campaign was organized. The experiment involved 9 subjects aged between 21 and 25 years (made up of about $62 \%$ of males and $38 \%$ of females) and with a driving experience between 2 and 5 years. The experiment was organized as follows. After the preliminary activities, i.e. privacy documents and socio-demo information, the subject was invited to sit on the simulator seat and to set height, inclination and distance from the steering wheel to reach a comfortable posture.

All subjects started the experiment by driving for 3 minutes through an adaptation scenario, in order to enable themselves to become more familiar with the simulator, and they were asked to check visibility, pedals and steering wheel reactions. Subsequently, the subjects carried out the actual experimental task: driving through the four testing scenarios, each one with different LOD, as discussed in previous sections. The duration of one-driving path was approximately 95 seconds, but it can be slightly different according to the driving style of the subject. Subjects run the path of the testing scenario twice for each LOD. At the end of the second lap, subjects were invited to stop driving and to answer the questions related to the driving experience. Further questions have been finally proposed to get an overall evaluation of the driving experience. A brief discussion on the driving experience was also held at the end of the overall driving session of each participant.

\section{Results and discussion}

Though the number of participants is still not enough for gaining definitive outcomes, anyhow it is interesting to start outlining the trends emerged. The results presented below are the first interpretation of the overall answers to the questionnaire filled up by the subjects before (socio-demo), during and after the (simulated) driving experience, and the brief discussion on the driving experience after the driving session. The direct talk was useful to go more in depth into the contents and specific meanings of the questionnaire synthetic answers.

Considering the comments of the subject we can argue essentially that:

- in scenarios with less environmental details (and particularly in Level 0) drivers direct their attention to what is poorly represented, e.g. fences, outer walls, facades; as the level of detail increases (Level I and Level 2), i.e. the scenario is more realistic, drivers' distraction gradually decreases;

- generally, the environmental elements, and particularly buildings, are perceived as relevant for aiding the driving;

- the simple road (Level 0 ) is generally perceived as fatiguing since the carriageway, not defined by buildings, is less easy to detect and the advantage of the major visibility in curvilinear segments does not counterbalance it; 
- the differences between models with no texture on facades, are difficult to distinguish, i.e. differences between Level I and Level 2 do not seem relevant;

- the absence of traffic and/or other living elements (pedestrians or animals) is generally perceived as unrealistic, and this affects the credibility of simulation;

- at a first glance, the sequence the scenarios with different LODs are presented to the subjects does not affect their evaluation.

In general, the answers to the questionnaire show a high degree of subjectiveness on the evaluation of scenarios and a further investigation is needed to get more reliable results.

\section{Conclusions}

Even if the outcomes of the first experiment presented in this paper should be further investigated for achieving more reliable outcomes, i.e. increasing the number of participants, it is possible to outline some preliminary considerations. As a matter of fact, the first results confirm that one of the main issues to carefully take into consideration when preparing a driving scenario is the level of realism. This is crucial for gaining a simulated experience comparable to the real one.This is not surprising, since in experiential simulation literature - even if not strictly related to driving simulators - this issue was already highlighted by several authors [Appleyard 1977; Bosselmann 1998; Sheppard 1989; Pietsch 2000; Rohrmann, Bishop 2002; Sheppard 2005; Piga, Morello 2015). Indeed, missing or poor details of the driving scenario negatively affect the fidelity of the driving simulation. It is then possible to assert that with simulation in motion, i.e. driving a car, the realism is still a crucial point, even if the number of perceivable details diminish with the increase of speed. The effort of producing a reliable, i.e. realistic, driving scenario is then still high and demanding, but it is probable that the trend of data sharing (from Google Maps $@$ or similar services) will reduce this effort in the future.

\section{References}

Appleyard, D. (1977). Understanding Professional Media. In I. Altman \& J. F. Wohlwill (eds). Human Behavior and Environment, pagg. 43-88. <http://link.springer.com/chapter/l0.1007/978-1-4684-0808-9_2>.

Arroyo Ohori K., Ledoux H., Biljecki F., Stoter J. (20I5). Modeling a 3D city model and its levels of detail as a true 4D model. In ISPRS International Journal of Geo-Information, 4, I055- 1075.

Becker Susanne, Haala N., Fritsch D. (2008). Combined knowledge propagation for facade reconstruction. In ISPRS CongresS 2008, pp. 423-430. Beijing, China: ISPRS.

Becker Susanne (2009). Generation and application of rules for quality dependent façade reconstruction. In ISPRS Journal of Photogrammetry and Remote Sensing, n. 64, pp. 640-653.

Becker Susanne (201 I). Towards complete LOD3 models - Automatic interpretation of building structures. In D. Fritsch (ed.). Proceedings of the 53rd photogrammetric week'I I, Stuttgart, Sept. 20 I. p. 39-56.

Biljecki F., Ledoux H., Stoter J., Zhao J. (20 I4). Formalisation of the level of detail in 3D city modelling. In Computers, Environment and Urban Systems, vol. 48, pp. I- I5.

Biljecki F., Ledoux H., Stoter J. (20 I6). An improved LOD specification for 3D building models. In Computers, Environment and Urban Systems, 59, 25-37.

Bishop lan. D., Lange E. (2005). Visualization in Landscape and environmental planning - Technology and applications. Oxon: Taylor \& Francis.

Bosselmann Peter, Craik, K. H. (1985). Perceptual simulation of environments. In Institute of Urban and Regional Development, (Working Paper No. 444), I-23.

Bosselmann Peter (1998). Representation of Places: Reality and Realism in City Design. Berkeley, Los Angeles, London: University of California Press.

Burrough P.A. (1986). Principles of geographical information systems for land resources assessment. New York: Oxford University Press.

Coors V., Hünlich K., On G. (2009). Constraint-based Generation and visualization of 3D city models. In J. Lee \& S. Zlatanova (eds.). 3D Geo-information Science (365-378). Berlin: Springer.

Döllner Jürgen, Baumann K., Buchholz H. (2006). Virtual 3D City Models as Foundation of Complex Urban Information Spaces. In M. Schrenk (ed.), I I th International Conference on Urban Planning and Spatial Development in the Information Society. Bremen, Nov. 2005, pp. I07-I I 2. New York: ACM. 
Döllner Jürgen, Buchholz H. (2005). Continuous level-of-detail modelling of buildings in virtual 3D city models. In C. Shahabi, O. Boucelma (eds.). 1 3th ACM International Symposium of Geographical Information Systems. Bremen, Nov. 2005, pp. I73- I 81. New York: ACM.

Döllner J., Hinrichs K. (2000). An object-oriented approach for integrating 3D visualization systems and GIS. In Computers \& Geosciences, 26, 67-76.

Dols Juan F., Molina J., Camacho-Torregrosa F.X., Marín-Morales J. et al. (2016). Design and development of driving simulator scenarios for road validation studies. CIT20I6 - XII Congreso de Ingeniería del Transporte València. Universitat Politècnica de València, 2016.

Fan H., Zipf A., Fu Q., Neis P. (20 I4). Quality assessment for building footprints data on OpenStreetMap. In International Journal of Geographical Information Science, 28, pp. 700-719.

Frueh Christian, Jain S., Zakhor A. (2005). Data Processing Algorithms for Generating Textured 3D Building Facade Meshes from Laser Scans and Camera Images. In International Journal of Computer Vision, 6I, pp. I 59- I 84.

Goetz Marcus (20 I 3). Towards generating highly detailed 3D CityGML models from OpenStreetMap. In International Journal of Geographical Information Science, 27, pp. 845-865.

Kang Zhizhong, Zhang L., Zlatanova S., Li J. (20 I0). An automatic mosaicking method for building facade texture mapping using a monocular close-range image sequence. In ISPRS Journal of Photogrammetry and Remote Sensing, 65, pp. 282-293.

Kolbe Thomas H. (2009). Representing and Exchanging 3D City Models with CityGML. In J. Lee \& S. Zlatanova (eds.). 3D Geoinformation Sciences. Berlin: Springer.

Lange Eckart (200 I). The limits of realism: perceptions of virtual landscapes. In Landscape and Urban Planning, 54, pp. I 63- I 82.

Luebke David, Reddy M., Cohen J.D., Varshney A. et al. (2003). Level of detail for 3D graphics. San Francisco: Morgan Kaufmann Pub.

Marans Robert W., \& Stokols, D. (eds.). (1993). Environmental Simulation: Research and Policy Issues. Berlin: Springer Science \& Business Media.

Mayer Helmut, Reznik S. (2007). Building facade interpretation from uncalibrated wide-baseline image sequences. In ISPRS Journal of Photogrammetry and Remote Sensing, 6I, 371-380.

Pettit Christopher, Cartwright W., Bishop I., et al. (eds.). (2008). Landscape Analysis and Visualization. Spatial Models for Natural Resource Management and PlanningBerlin: Springer.

Pietsch susan M. (2000). Computer visualisation in the design control of urban environments: A literature review. In Environment and Planning B, 27(4), 52 I-536.

Piga Barbara Ester Adele, Morello, E. (20I5). Environmental Design Studies on Perception and Simulation: An Urban Design Approach. In International Journal of Sensory Environment, Architecture and Urban Space. <http://ambiances.revues.org/647>

Pittman Ken ( 1992). A laboratory for the visualization of virtual environments. In Landscape and Urban Planning, 21, 327-33I.

Rohrmann Bernd, Bishop, I. (2002). Subjective Responses to Computer Simulations of Urban Environments. In Journal of Environmental Psychology, 22(4), 319-331. <https://doi.org/10.1006/jevp.2001.0206>,

Sheppard Stephen R. J. (2005).Validity, reliability and ethics in visualization. In I. Bishop \& E. Lange (eds.). Visualization in Landscape and environmental Planning. New York: Routledge - Taylor and Francis Group, pp. 79-97.

Sheppard Stephen R. J. (1989). Visual Simulation: A User Guide for Architects, Engineers, and Planners. New York:Van Nostrand Reinhold.

Touya Guillaume, Reimer A. (20 I 5). Inferring the scale of OpenStreetMap features. In J.J.Arsanjani, A. Zipf, P. Mooney, M. Helbich (eds.), OpenStreetMap in GIScience. Berlin: Springer International Publishing. Pp. 8I-99.

Wang Chun, Chen G., Liu Y., Horne M. (2008). Virtual-Reality Based Integrated Traffic Simulation for Urban Planning. International Conference on Computer Science and Software Engineering, IEEE, Wuhan, China, vol.2, I I 37 - I I 40.

\section{Websites}

$<$ CarMaker, https://ipg-automotive.com/>.

$<$ CityGML, https://www.citygml.org/>.

$<$ Citygml Wiki, http://www.citygmlwiki.org/>.

<SketchUp, https://www.sketchup.com/>

\section{Authors}

Barbara Piga, Politecnico di Milano, barbara.piga@polimi.it

Giandomenico Caruso, Politecnico di Milano, giandomenico.caruso@polimi.it

Alfonso Ferraioli, Politecnico di Milano, alfonso.ferraioli@mail.polimi.it

Lorenzo Mussone, Politecnico di Milano, lorenzo.mussone@polimi.it

To cite this chapter. Piga Barbara, Caruso Giandomenico, Ferraioli Alfonso, Mussone Lorenzo (2020). Modeling virtual road scenarios for driving simulators: a comparison of 3D models with different level of details. In Arena A., Arena M., Brandolino R.G., Colistra D., Ginex G., Mediati D.
Nucifora S., Raffa P. (a cura di). Connettere. Un disegno per annodare e tessere. Atti del $42^{\circ}$ Convegno Internazionale dei Docenti delle Discipline Nucifora S., Raffa P. (a cura di). Connettere. Un disegno per annodare e tessere. Atti del $42^{\circ}$ Convegno Internazionale dei Docenti delle Discipline
della Rappresentazione/Connecting. Drawing for weaving relationships. Proceedings of the 42 th International Conference of Representation Disciplines Teachers. Milano: FrancoAngeli, pp. $792-802$. 